\title{
CDC updates Zika virus guidance to protect pregnant women
}

\author{
Michael McCarthy
}

Seattle

In response to reports linking Zika virus infection to fetal abnormalities, including microencephaly, and to the recent report of sexual transmission of the virus in Texas, ${ }^{1}$ the US Centers for Disease Control and Prevention has updated its guidance on the virus.

The updates, released on 5 February, recommended that men who reside in or who have traveled to an area where there is active transmission of the Zika virus and who have a pregnant sexual partner should either abstain from sexual activity or use condoms during sex, including vaginal and anal intercourse and fellatio, for the duration of the pregnancy. ${ }^{2} 3$ "Pregnant women should discuss their male partner's potential exposures to mosquitoes and history of Zika-like illness with their health care provider," the CDC said.

CDC officials acknowledged that their information on sexual transmission of the virus was limited, being based on just three case reports. It is not known, for example, how long Zika virus persists in semen, whether infected men who have never developed symptoms can transmit the virus to their sexual partners, or whether infected women can transmit the virus to their male partners.

Because there is no vaccine or drug to prevent Zika virus infections nor specific antiviral treatment for infection, all pregnant women should consider postponing travel to areas with active Zika transmission, the CDC said. Pregnant women who do travel to areas where the virus is being transmitted should strictly follow steps to avoid mosquito bites, such as wearing long sleeved shirts and long pants, using approved insect repellents, and staying in screened and air-conditioned rooms, the CDC said.

Pregnant women who have traveled to areas with ongoing Zika virus transmission should be offered serologic testing in 2-12 weeks after returning, whether or not they have had symptoms of infection, the CDC said. Pregnant women who live in areas where transmission is ongoing and who develop symptoms consistent with Zika virus disease should be tested during the first week of the illness. Asymptomatic pregnant women living in these areas should be tested at the initiation of prenatal care, with follow-up testing in the middle of the second trimester, the CDC said.

The guidance also provided additional recommendations concerning monitoring and follow-up care, including the use of fetal ultrasonography to detect fetal abnormalities.

For all The BMSs latest articles on the Zika virus epidemic go to bmj. co/zika.

McCarthy M. Zika virus was transmitted by sexual contact in Texas, health officials report.
BMJ 2016;352:i720.
Oster AM, Brooks JT, Stryker JE, et al. Interim guidelines for prevention of sexual
transmission of Zika virus-United States, 2016. MMWR Morb Mortal Wkly Rep 5 Feb
2015, doi:10.15585/mmwr.mm6505e1er.
Oduyebo T, Petersen EE, Rasmussen SA, et al. Update: interim guidelines for health
care providers caring for pregnant women and women of reproductive age with possible
Zika virus exposure-United States, 2016. MMWR Morb Mortal Wkly Rep 5 Feb 2015,
doi:10.15585/mmwr.mm6505e2er.
Cite this as: BMJ 2016;352:i786
BMJ Publishing Group Ltd 2016 